\title{
Expenditure and financial burden for the diagnosis and treatment of colorectal cancer in China: a hospital-based, multicenter, cross-sectional survey
}

Hui-Yao Huang ${ }^{1}$, Ju-Fang Shi ${ }^{1 *}$, Lan-Wei Guo ${ }^{1,2}$, Ya-Na Bai ${ }^{3}$, Xian-Zhen Liao ${ }^{4}$, Guo-Xiang Liu ${ }^{5}$, A-Yan Mao ${ }^{6}$, Jian-Song Ren ${ }^{1}$, Xiao-Jie Sun ${ }^{7}$, Xin-Yu Zhu ${ }^{1,3}$, Le Wang ${ }^{1}$, Bing-Bing Song ${ }^{8}$, Ling-Bin Du ${ }^{9}$, Lin Zhu ${ }^{10}$, Ji-Yong Gong ${ }^{11}$, Qi Zhou ${ }^{12}$, Yu-Qin Liư ${ }^{13}$, Rong Cao ${ }^{14}$, Ling Mai ${ }^{15}$, Li Lan $^{16}$, Xiao-Hua Sun ${ }^{17}$, Ying Ren ${ }^{18}$, Jin-Yi Zhou ${ }^{19}$, Yuan-Zheng Wang ${ }^{20}$, Xiao Qi ${ }^{21}$, Pei-An Lou ${ }^{22}$, Dian Shi ${ }^{1,3}, \mathrm{Ni}_{\mathrm{Li}}{ }^{1}, \mathrm{Kai}_{\text {Zhang }}{ }^{1}$, Jie He $\mathrm{H}^{1}$ and Min Dai ${ }^{{ }^{*}}$

\begin{abstract}
Background: The increasing prevalence of colorectal cancer (CRC) in China and the paucity of information about relevant expenditure highlight the necessity of better understanding the financial burden and effect of CRC diagnosis and treatment. We performed a survey to quantify the direct medical and non-medical expenditure as well as the resulting financial burden of CRC patients in China.

Methods: We conducted a multicenter, cross-sectional survey in 37 tertiary hospitals in 13 provinces across China between 2012 and 2014. Each enrolled patient was interviewed using a structured questionnaire. All expenditure data were inflated to the 2014 Chinese Yuan (CNY; 1 CNY $=0.163$ USD). We quantified the overall expenditure and financial burden and by subgroup (hospital type, age at diagnosis, sex, education, occupation, insurance type, household income, clinical stage, pathologic type, and therapeutic regimen). We then performed generalized linear modeling to determine the factors associated with overall expenditure.
\end{abstract}

Results: A total of 2356 patients with a mean age of 57.4 years were included, $57.1 \%$ of whom were men; $13.9 \%$ of patients had stage I cancer; and the average previous-year household income was 54,525 CNY. The overall average direct expenditure per patient was estimated to be $67,408 \mathrm{CNY}$, and the expenditures for stage I, II, III, and IV disease were 56,099 CNY, 59,952 CNY, 67,292 CNY, and 82,729 CNY, respectively. Non-medical expenditure accounted for 8.3\% of the overall expenditure. The 1-year out-of-pocket expenditure of a newly diagnosed patient was 32,649 CNY, which accounted for $59.9 \%$ of their previous-year household income and caused $75.0 \%$ of families to suffer an unmanageable financial burden. Univariate analysis showed that financial burden and overall expenditure differed in almost all subgroups $(P<0.05)$, except for sex. Multivariate analysis showed that patients who were treated in specialized hospitals and those who were diagnosed with adenocarcinoma or diagnosed at a later stage were likely to spend more, whereas those with a lower household income and those who underwent surgery spent less (all $P<0.05$ ).

Conclusions: For patients in China, direct expenditure for the diagnosis and treatment of CRC seemed catastrophic, and non-medical expenditure was non-ignorable. The financial burden varied among subgroups, especially among patients with different clinical stages of disease, which suggests that, in China, CRC screening might be cost-effective.

\footnotetext{
*Correspondence: shijf@cicams.ac.cn; daimin2002@hotmail.com

1 Program Office for Cancer Screening in Urban China, National Cancer Center/Cancer Hospital, Chinese Academy of Medical Sciences, Peking Union Medical College, 17 South Panjiayuan Lane, Chaoyang District, Beijing 100021, P. R. China

Full list of author information is available at the end of the article
} 
Keywords: Colorectal neoplasms, Direct expenditure, Financial burden, China

\section{Background}

Worldwide, colorectal cancer (CRC) is the third most commonly diagnosed cancer in men and the fourth most common in women [1]. It was estimated that, in 2012, 159,100 new male cases and 142,200 new female cases occurred in China [2]. Significant advances have been made worldwide in improving CRC patient survival, which are bound to increase the financial burden at the aggregate level, especially in the context of high prevalence and rapid population growth [1,3]. It has been shown that patients and their families suffer both financial burden and emotional hardship [4-6]. Considerable researches have been conducted on the financial burden of cancer in the United States and other countries [7, 8]. Studies in China have been scarce, and most such studies have focused merely on the medical expenditure, as documented from hospital information systems [9].

Discerning the true financial burden helps explain the general status of a population's health under current healthcare system, thus enabling the development of optimal policies. Furthermore, a sound understanding of the financial burden is crucial for conducting cost-effective analyses; also, it helps assess the potential expenditures and benefits of related intervention programs [10]_for example, whether the screening strategies involved in the ongoing Cancer Screening Program in Urban China (CanSPUC) are cost-effective at the current scale or an expanded scale in the future [11]. This work is of great importance in the context of limited evidence on the economic evaluation of CRC screening in China [12].

Conducted as part of the health economic evaluation research of the CanSPUC, this study aimed to estimate both medical and non-medical expenditures of overall and subgroups of CRC patients, as well as to discern the subsequent financial burdens imposed on patient families.

\section{Methods}

\section{Study design and study sites}

This multicenter, hospital-based, cross-sectional study was conducted between September 2012 and December 2014 in 13 study sites (Shandong, Beijing, Jiangsu, Guangdong, Zhejiang, Hebei, Liaoning, Hunan, Heilongjiang, Henan, Xinjiang, Gansu, and Chongqing). The 13 sites joined in the first 2 years after the CanSPUC startup. Thirty-seven tertiary hospitals (23 general hospitals and 14 specialized hospitals) were involved. Table 1 shows further information about the involved cities and hospitals, including population size, gross domestic product (GDP) per capita, and numbers of cities and hospitals for each site [13]. The survey was approved by the Institutional Review Board of the Cancer Hospital of the Chinese Academy of Medical Sciences. All patients provided written informed consent.

\section{Patient selection}

Considering the budget from the government and previous experience, a total of 3120 CRC patients were expected for the 13 study sites. For each site, in accordance with a uniform design scheme, a stratified convenience sampling approach was used for selecting 240 clinically confirmed, primary prevalent CRC patients who were undergoing treatment in hospitals (including both newly diagnosed and existing cancer patients). To reach a sufficient power for subgroup analyses, sample sizes were balanced among cancer stages $(20 \%-30 \%$ for each stage, from stage I to stage IV) and sex (maximum $60 \%$ for either sex). All respondents were interviewed face-to-face using a structured questionnaire at the time of discharge when most treatment expenses were incurred. Prior to the survey, we registered participation of all invited patients; also, we recorded basic information to facilitate exclusion, including age, sex, and cancer stage. For patients who were in very poor condition, family member(s) or other caregivers helped with the interview; all other interviewees were the patients themselves.

\section{Questionnaire contents}

The questionnaire included the following five parts: (A) demographic and societal information (e.g., hospital ID, name, sex, age, education, occupation, previous-year household income, and healthcare insurance type); (B) clinical information (e.g., clinical stage, pathologic diagnosis, confirmed date, and therapeutic regimen); (C) expenditure information of the to-date whole course of illness until the survey date by clinical visit-both outpatient and inpatient, occurring both within and outside the surveyed hospitals-i.e., the start date of treatment, hospitalization duration, overall medical expenditure, overall and detailed non-medical expenditure (including additional meals, additional nutrition, transportation, accommodation, hired informal nursing, and other expenditures), predicted reimbursement ratio, and selfreported financial pressure; (D) time loss of the to-date whole course to clinical visits (both outpatient and inpatient, occurring both within and outside the surveyed hospitals) - patient working days lost and accompanying 
Table 1 Summary information and overall expenditure for diagnosis and treatment of patients with colorectal cancer in 13 study sites in China

\begin{tabular}{|c|c|c|c|c|c|c|c|}
\hline \multirow[t]{2}{*}{ Province } & \multicolumn{2}{|c|}{ General information } & \multicolumn{4}{|c|}{ Specific information on cites and hospitals involved } & \multirow{2}{*}{$\begin{array}{l}\text { Overall } \\
\text { expenditure } \\
\text { (CNY) }\end{array}$} \\
\hline & $\begin{array}{l}\text { Population } \\
\text { size in } 2014^{\mathrm{a}} \\
(\times 10,000)\end{array}$ & $\begin{array}{l}\text { GDP per capita } \\
\text { in } 2014^{\mathrm{a}} \text { (CNY) }\end{array}$ & $\begin{array}{l}\text { Number } \\
\text { of cities }\end{array}$ & $\begin{array}{l}\text { Total number } \\
\text { of hospitals }\end{array}$ & $\begin{array}{l}\text { Number } \\
\text { of general } \\
\text { hospitals }\end{array}$ & $\begin{array}{l}\text { Number of } \\
\text { specialized } \\
\text { hospitals }\end{array}$ & \\
\hline Shandong & 9789 & 60,879 & 1 (Jinan) & 1 & 0 & 1 & 111,813 \\
\hline Beijing & 2152 & 99,995 & 1 (Beijing) & 3 & 1 & 2 & 94,502 \\
\hline Xinjiang & 2298 & 40,648 & 1 (Urumchi) & 2 & 0 & 2 & 88,887 \\
\hline Hunan & 6737 & 40,271 & 1 (Changsha) & 6 & 5 & 1 & 70,168 \\
\hline Guangdong & 10,724 & 58,540 & 5 (Five cities ${ }^{b}$ ) & 2 & 1 & 1 & 69,238 \\
\hline Zhejiang & 5508 & 73,002 & $\begin{array}{l}2 \text { (Hangzhou, } \\
\text { Ningbo) }\end{array}$ & 3 & 3 & 0 & 65,952 \\
\hline Heilongjiang & 3833 & 39,226 & 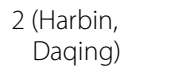 & 1 & 1 & 0 & 60,245 \\
\hline Gansu & 2591 & 26,433 & 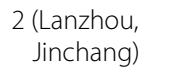 & 1 & 0 & 1 & 56,126 \\
\hline Henan & 9436 & 37,072 & 1 (Zhengzhou) & 6 & 5 & 1 & 55,829 \\
\hline Hebei & 7384 & 39,984 & 1 (Tangshan) & 1 & 0 & 1 & 49,332 \\
\hline Jiangsu & 7960 & 81,874 & $\begin{array}{l}2 \text { (Nantong, } \\
\text { Xuzhou) }\end{array}$ & 1 & 0 & 1 & 46,181 \\
\hline Liaoning & 4391 & 65,201 & 1 (Tieling) & 9 & 7 & 2 & 37,103 \\
\hline Chongqing & 2991 & 47,850 & 1 (Chongqing) & 1 & 0 & 1 & 36,292 \\
\hline National total & 136,782 & 46,652 & 21 & 37 & 23 & 14 & $67,408^{c}$ \\
\hline
\end{tabular}

CNY Chinese Yuan, GDP gross domestic product

a Based on China Statistical Yearbook 2015. http://www.stats.gov.cn/tjsj/ndsj/2015/indexch.htm [13]

b Including Guangzhou, Shenzhen, Zhongshan, Dongguan, and Foshan

c The average overall expenditure for colorectal cancer diagnosis and treatment based on data from the 13 study sites in China

person-days of informal caregivers (relatives and friends); and (E) quality control items (e.g., investigator-evaluated reliability (excellent, good, general, or poor) of the above four parts, and signature of investigator and auditor). If the former four parts were evaluated as excellent or good reliability, the record was deemed as high quality; otherwise, it was considered as low quality.

\section{Estimation of expenditure and financial burden}

We estimated the overall expenditure per patient for the whole course of illness, including both medical and non-medical expenditures. Medical expenditures were paid partly by the insurers; non-medical expenditures were paid entirely by the patients. We defined a newly diagnosed course as 2 months before diagnosis and 10 months after diagnosis, which is not exactly the same as the commonly used definition (1 year after diagnosis) because, in China, a large amount of money is usually spent for diagnosis before pathologic confirmation. We defined all patient-paid medical expenditure items and non-medical expenditure of a newly diagnosed course as out-of-pocket expenditure. Expenditure data presented estimates for the whole course of the illness if they were unspecified. Except when calculating the proportional breakdown of non-medical expenditures, all expenditure data were converted to the 2014 Chinese Yuan (CNY; 1 $\mathrm{CNY}=0.163 \mathrm{USD}$ ) by the year-specific healthcare consumer price index of China [13].

To qualify financial pressure, we asked, "Which of the following accurately describes your family's financial pressure from your disease?" and offered four response options: "not at all," "somewhat but manageable," "heavy," and "overwhelmed." We classified "not at all" and "somewhat but manageable" as manageable burdens; we classified the other two responses as unmanageable burdens. In addition, to objectively reflect the financial burden, we adapted the indicator of the expense-income ratio, which equals to the average out-of-pocket expense of a newly diagnosed course divided by the average previous-year household income. We used the threshold proposed by $\mathrm{Xu}$ et al. [14] that financial catastrophe occurs with the expense-income ratio at or exceeding $40 \%$.

\section{Statistical analysis}

For quality control purposes, all investigators were trained and required to check each questionnaire before ending the survey; a second research staff member would then double-check each questionnaire within 2 days of 
completion. All data were double-entered into EpiData 3.1 software (EpiData Association, Odense, Denmark). In addition, extensive data checking was performed using SAS 9.2 statistical software (SAS Institute, Cary/NC, USA).

SAS 9.2 statistical software was also used for data analysis. For descriptive analysis, we used percentages for qualitative variables; due to the skewed nature of quantitative variables (such as expenditure estimates), several descriptive statistics was derived as needed, including means, standard deviations, medians, and ranges. We conducted a subgroup analysis of the overall expenditure, expense-income ratio, financial pressure, and time loss by using the following variables: hospital type, age at diagnosis, sex, education, occupation, healthcare insurance type, previous-year household income, clinical stage, pathologic type, and therapeutic regimen. For the overall expenditure after logarithm transition, expense-income ratio, and time loss, a two-sample Student's $t$ test was used for a two-group comparative analysis; the analysis of variance test was used for more than two groups; and the SNK- $q$ test was used for multiple comparisons. The overall expenditure of each study site was also calculated, and its spearman correlation with site-specific GDP per capita in 2014 was explored. To determine financial pressure, the Chi square test was used. To determine the influencing factors of overall expenditure, we also performed generalized linear modeling with a gamma distribution. $P$ values less than 0.05 were considered statistically significant.

\section{Results}

\section{Descriptive characteristics}

We invited 2710 CRC patients; however, 354 (15.5\%) did not participate in the survey. The main reasons for nonparticipation were strong refusal by patients $(74.0 \%)$, followed by communication difficulties (13.0\%), and strong refusal by relatives (3.4\%). A total of 2356 CRC patients were finally included, with a mean age at diagnosis of 57.4 years. Of these patients, 1660 (70.5\%) came from specialized hospitals; 1345 (57.1\%) were men; 253 (10.7\%) had college education or above; and 845 (35.9\%) were farmers (Table 2). The two principal insurance types were the urban employee basic medical insurance (916 of $2356,38.9 \%)$ and the new rural cooperative medical scheme (897 of 2356, 38.1\%). The mean previous-year household income was 54,525 CNY.

The proportions of stage I, II, III, and IV disease were $13.9,26.7,34.6$, and $23.7 \%$, respectively. In terms of pathologic type, most was adenocarcinoma (88.3\%). Approximately one-third $(37.8 \%)$ of the patients underwent surgery alone; another third (33.4\%) received chemotherapy alone. The median numbers of clinical visits and
Table 2 Characteristics of 2356 patients with colorectal cancer

\begin{tabular}{|c|c|}
\hline Characteristic & No. of patients (\%) \\
\hline \multicolumn{2}{|l|}{ Hospital type } \\
\hline General & $696(29.5)$ \\
\hline Specialized & $1660(70.5)$ \\
\hline \multicolumn{2}{|l|}{ Age at diagnosis (years) } \\
\hline Mean $\pm S D^{a}$ & $57.4 \pm 12.1$ \\
\hline$<45$ & $361(15.3)$ \\
\hline $45-54$ & $542(23.0)$ \\
\hline $55-64$ & $787(33.4)$ \\
\hline$\geq 65$ & $666(28.3)$ \\
\hline \multicolumn{2}{|l|}{ Sex } \\
\hline Men & $1345(57.1)$ \\
\hline Women & $1011(42.9)$ \\
\hline \multicolumn{2}{|l|}{ Education } \\
\hline Primary school or below & $727(30.9)$ \\
\hline Junior high school & $784(33.3)$ \\
\hline Senior high school & $592(25.1)$ \\
\hline Undergraduate or over & $253(10.7)$ \\
\hline \multicolumn{2}{|l|}{ Occupation } \\
\hline Farmer & $845(35.9)$ \\
\hline Enterprise or company employee/worker & $570(24.2)$ \\
\hline Self-employee or unemployee & $354(15.0)$ \\
\hline Retiree & $274(11.6)$ \\
\hline Public sector employee & $259(11.0)$ \\
\hline Others & $54(2.3)$ \\
\hline \multicolumn{2}{|l|}{ Previous-year household income ${ }^{a, b}$ (CNY) } \\
\hline Mean \pm SD & $54,525 \pm 45,822$ \\
\hline Median $\left(\mathrm{P}_{25}-\mathrm{P}_{75}\right)$ & $40,000(20,000-70,000)$ \\
\hline$<20,000$ & $339(14.9)$ \\
\hline $20,000-39,999$ & $632(27.7)$ \\
\hline $40,000-69,999$ & $669(29.4)$ \\
\hline$\geq 70,000$ & $639(28.0)$ \\
\hline \multicolumn{2}{|l|}{ Income per patient in last 5 years ${ }^{\mathrm{a}, \mathrm{c}}(\mathrm{CNY})$} \\
\hline Mean \pm SD & $30,355 \pm 29,841$ \\
\hline Number of family members ${ }^{\mathrm{a}, \mathrm{d}}\left[\right.$ median $\left.\left(\mathrm{P}_{25}-\mathrm{P}_{75}\right)\right]$ & $4(2-5)$ \\
\hline \multicolumn{2}{|l|}{ Healthcare insurance type ${ }^{e}$} \\
\hline Urban employee basic medical insurance & $916(38.9)$ \\
\hline Urban resident basic medical insurance & $446(18.9)$ \\
\hline New rural cooperative medical scheme & $897(38.1)$ \\
\hline Commercial insurance & $22(0.9)$ \\
\hline Self-paid & $49(2.1)$ \\
\hline Others & $24(1.0)$ \\
\hline \multicolumn{2}{|l|}{ Clinical stage } \\
\hline । & $328(13.9)$ \\
\hline$\|$ & $630(26.7)$ \\
\hline III & $815(34.6)$ \\
\hline IV & $559(23.7)$ \\
\hline Not reported & $24(1.0)$ \\
\hline \multicolumn{2}{|l|}{ Pathologic type } \\
\hline Adenocarcinoma & 2081 (88.3) \\
\hline
\end{tabular}


Table 2 continued

\begin{tabular}{ll}
\hline Characteristic & No. of patients (\%) \\
\hline Others & $176(7.5)$ \\
Not reported & $99(4.2)$ \\
Therapeutic regimen ${ }^{f}$ & \\
Surgery & $886(37.8)$ \\
Chemotherapy & $784(33.4)$ \\
Surgery and postoperative chemotherapy & $333(14.2)$ \\
Symptomatic treatment & $222(9.5)$ \\
Concurrent chemoradiotherapy & $62(2.6)$ \\
Radiotherapy & $42(1.8)$ \\
Neoadjuvant chemotherapy and surgery & $16(0.7)$ \\
Number of clinical visits ${ }^{\mathrm{a}}$ [median $\left.\left(\mathrm{P}_{5}-\mathrm{P}_{95}\right)\right]$ & $2(1-5)$ \\
Number of admissions ${ }^{\mathrm{a}}$ [median $\left.\left(\mathrm{P}_{5}-\mathrm{P}_{95}\right)\right]$ & $1(1-5)$ \\
Hospital stay ${ }^{\mathrm{a}, 9}$ (days) & \\
Mean $\pm \mathrm{SD}$ & $37 \pm 38$ \\
Median $\left(\mathrm{P}_{25}-\mathrm{P}_{75}\right)$ & $25(17-42)$ \\
Quality of the questionnaire & \\
High quality & $2230(94.7)$ \\
Low quality & $126(5.3)$
\end{tabular}

$S D$ standard deviation, $C N Y$ Chinese Yuan, $P_{25}-P_{75}$ percentile 25 to percentile 75 , $P_{5}-P_{95}$ percentile 5 to percentile 95

a Except for these values, other values are presented as number of patients followed by percentage in parentheses

b The data of 77 patients were missing

c The data of 44 patients were missing

${ }^{d}$ The data of 24 patients were missing

e The data of 2 patients were missing

${ }^{f}$ The data of 11 patients were missing

${ }^{g}$ The data of 4 patients were missing

admissions were 2 (percentile 5 to percentile $95\left[\mathrm{P}_{5}-\mathrm{P}_{95}\right]$ : $1-5)$ and $1\left(\mathrm{P}_{5}-\mathrm{P}_{95}: 1-5\right)$, respectively. The median hospital duration was 25 days (percentile 25 to percentile $75\left[\mathrm{P}_{25}-\mathrm{P}_{75}\right]: 17-42$ days), and the median course was 36 days $\left(\mathrm{P}_{25}-\mathrm{P}_{75}: 12-124\right.$ days $)$. Of the whole patient cohort, 2230 (94.7\%) provided responses that were considered high quality. More information about the questionnaires is shown in Table 2.

\section{Overall expenditure}

Overall mean expenditure per CRC patient was estimated to be $67,408 \mathrm{CNY}$, with $91.7 \%(61,829 \mathrm{CNY})$ used for medical expenditure. Overall expenditure showed a notable increase with the progression of disease $(P<0.001)$ : for stages I, II, III, and IV disease, the expenditures were 56,099 CNY (95\% confidence interval [CI] 51,918-60,281 CNY), 59,952 CNY (95\% CI 56,971-62,932 CNY), 67,292 CNY (95\% CI 63,673-70,910 CNY), and 82,729 CNY (95\% CI 77,231-88,228 CNY), respectively. Multiple comparisons of overall expenditure showed that no significant difference was found between stage I and II, I and
III, or II and III diseases (all $P>0.05$ ); overall expenditure for stage IV disease was significantly higher than that for stages I-III diseases $(P<0.001)$. Multiple comparison of medical expenditure showed similar results; medical expenditure ranged from 51,366 CNY (95\% CI 47,644$55,087 \mathrm{CNY})$ for stage I disease to $75,673 \mathrm{CNY}$ (95\% CI 70,551-80,794 CNY) for stage IV disease, with a $47.5 \%$ growth rate. Detailed information about medical expenditure for CRC diagnosis and treatment is shown in Fig. 1.

We found that the overall expenditure varied among different study sites (range 36,292-111,813 CNY), with Chongqing the lowest and Shandong the highest (Table 1). Spearman correlation analysis showed that the expenditure was not associated with the local economy ( $r=0.143, P=0.626)$. Thus, the GDP per capita was not considered in the later univariate and multivariate analyses.

Univariate analysis showed significant differences in all subgroup comparisons, except for sex $(P=0.181)$. Patients in specialized hospitals $(P<0.001)$, those who were diagnosed with adenocarcinoma $(P<0.001)$ or were diagnosed at an earlier age $(P=0.034)$, or those who were well-educated (undergraduate or higher) $(P<0.001)$ were likely to spend more compared with their control groups, whereas self-employed or unemployed patients $(P<0.001)$, underinsured patients (self-paid) $(P=0.007)$, those with a lower household income $(P<0.001)$, or who were treated with surgery $(P<0.001)$ spent less. Multivariate analysis confirmed that patients in specialized hospitals $(P<0.001)$, patients who were diagnosed with adenocarcinoma $(P<0.001)$, or patients who were diagnosed at stage IV

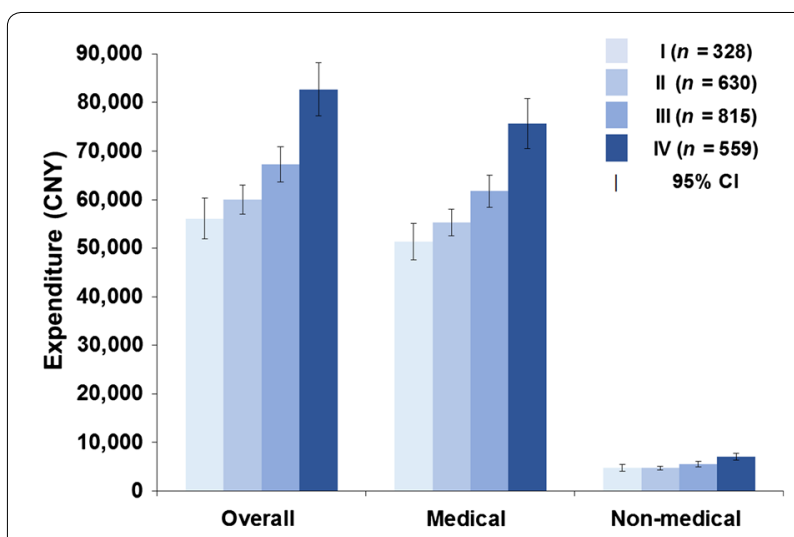

Fig. 1 Medical and non-medical expenditures for diagnosis and treatment of patients with stage I-IV colorectal cancer. CNY Chinese Yuan, $\mathrm{Cl}$ confidence interval. Of the 2356 patients included, 24 have no information of clinical stage 
$(P<0.001)$ were likely to spend more, whereas patients with lower household income $(P=0.006)$ or who received surgery $(P<0.001)$ spent less compared with their control groups. Detailed expenditure comparison results are shown in Tables 3 and 4.

\section{Non-medical expenditure}

Non-medical expenditure accounted for $8.3 \%$ of the overall expenditure (5588 CNY per CRC patient). Additional meal contributed the largest proportion (1566 CNY, $28.0 \%$ ), followed by transportation (1089 CNY, 19.5\%)

Table 3 Univariate analysis of overall expenditure for diagnosis and treatment of 2356 patients with colorectal cancer

\begin{tabular}{|c|c|c|c|c|c|}
\hline \multirow[t]{2}{*}{ Variable } & \multicolumn{3}{|c|}{ Expenditure (CNY) } & \multirow[t]{2}{*}{ Statistics $^{a}$} & \multirow[t]{2}{*}{$P^{a}$} \\
\hline & Medical & Non-medical & Overall & & \\
\hline Total & 61,829 & 5579 & 67,408 & - & - \\
\hline \multicolumn{6}{|l|}{ Hospital type } \\
\hline General & 52,392 & 4893 & 57,285 & \multirow[t]{2}{*}{-4.46} & \multirow[t]{2}{*}{$<0.001$} \\
\hline Specialized & 65,786 & 5866 & 71,652 & & \\
\hline \multicolumn{6}{|l|}{ Age at diagnosis (years) } \\
\hline$<45$ & 65,887 & 6122 & 72,009 & \multirow[t]{4}{*}{2.90} & \multirow[t]{4}{*}{0.034} \\
\hline $45-54$ & 66,303 & 6049 & 72,352 & & \\
\hline $55-64$ & 59,416 & 5328 & 64,744 & & \\
\hline$\geq 65$ & 58,840 & 5198 & 64,038 & & \\
\hline \multicolumn{6}{|l|}{ Sex } \\
\hline Men & 62,526 & 5751 & 68,277 & \multirow[t]{2}{*}{1.34} & \multirow[t]{2}{*}{0.181} \\
\hline Women & 60,903 & 5350 & 66,253 & & \\
\hline \multicolumn{6}{|l|}{ Education } \\
\hline Primary school or below & 57,354 & 4883 & 62,237 & \multirow[t]{4}{*}{8.36} & \multirow[t]{4}{*}{$<0.001$} \\
\hline Junior high school & 58,898 & 5191 & 64,089 & & \\
\hline Senior high school & 65,095 & 5805 & 70,900 & & \\
\hline Undergraduate or higher & 76,132 & 8250 & 84,382 & & \\
\hline \multicolumn{6}{|l|}{ Occupation } \\
\hline Farmer & 57,796 & 4973 & 62,769 & \multirow[t]{6}{*}{8.19} & \multirow[t]{6}{*}{$<0.001$} \\
\hline Enterprise or company employee/worker & 63,563 & 5859 & 69,422 & & \\
\hline Self-employee or unemployee & 54,449 & 4640 & 59,089 & & \\
\hline Retiree & 70,629 & 7835 & 78,464 & & \\
\hline Public sector employee & 72,707 & 5628 & 78,335 & & \\
\hline Others & 58,197 & 6579 & 64,776 & & \\
\hline \multicolumn{6}{|l|}{ Healthcare insurance type } \\
\hline Urban employee basic medical insurance & 66,458 & 6289 & 72,747 & \multirow[t]{6}{*}{3.17} & \multirow[t]{6}{*}{0.007} \\
\hline Urban resident basic medical insurance & 60,118 & 4861 & 64,979 & & \\
\hline New rural cooperative medical scheme & 58,046 & 5062 & 63,108 & & \\
\hline Commercial insurance & 61,233 & 2958 & 64,191 & & \\
\hline Self-paid & 53,914 & 5855 & 59,769 & & \\
\hline Others & 78,293 & 13,023 & 91,316 & & \\
\hline \multicolumn{6}{|l|}{ Previous-year household income (CNY) } \\
\hline$<20,000$ & 53,581 & 4570 & 58,151 & \multirow[t]{4}{*}{5.75} & $<0.001$ \\
\hline $20,000-39,999$ & 61,461 & 5193 & 66,654 & & \\
\hline $40,000-69,999$ & 62,972 & 5586 & 68,558 & & \\
\hline$\geq 70,000$ & 65,371 & 6188 & 71,559 & & \\
\hline Pathologic type & & & & & \\
\hline Adenocarcinoma & 62,759 & 5636 & 68,395 & 3.35 & $<0.001$ \\
\hline Others & 53,279 & 4501 & 57,780 & & \\
\hline Therapeutic regimen & & & & & \\
\hline Surgery & 51,759 & 3812 & 55,571 & 14.04 & $<0.001$ \\
\hline Chemotherapy & 68,749 & 6818 & 75,567 & & \\
\hline
\end{tabular}


Table 3 continued

\begin{tabular}{lllll}
\hline Variable & \multicolumn{2}{l}{ Expenditure (CNY) } & Statistics $^{\mathbf{a}}$ & $\boldsymbol{P}^{\mathbf{a}}$ \\
\cline { 2 - 3 } & Medical & Non-medical & Overall \\
\hline Surgery and postoperative chemotherapy & 63,068 & 5702 & 68,770 \\
Symptomatic treatment & 55,970 & 5237 & 61,207 \\
Concurrent chemoradiotherapy & 114,491 & 12,944 & 127,435 \\
Radiotherapy & 88,857 & 7989 & 96,846 \\
Neoadjuvant chemotherapy and surgery & 71,557 & 9682 & 81,239 \\
\hline
\end{tabular}

CNY Chinese Yuan

a Two-sample Student's $t$ test after logarithm transition was used for binary classification variables, including hospital type, sex, and pathologic type; analysis of variance test after logarithm transition was used for other multiple categorical variables, including age at diagnosis, education, occupation, insurance type, household income, and therapeutic regimen

and additional nutrition (1075 CNY, 19.2\%). Multiple comparisons of non-medical expenditure between CRC patients stage I-IV disease showed differences between all the two subgroups except stages II and III. Figures 1 and 2 show more detailed information about non-medical expenditure.

\section{Financial burden}

As a whole, the overall expenditure of a newly diagnosed illness course was 58,778 CNY, accounting for $87.2 \%$ of that of the to-date whole course of illness. With the predicted reimbursement ratio equaling $46.5 \%$, out-ofpocket expenditure amounted to 32,649 CNY, accounting for $59.9 \%$ of the previous-year household income. That made $75.0 \%$ of the families perceive an unmanageable burden (47.4\% heavy, $27.6 \%$ overwhelmed); only $18.3 \%$ perceived a somewhat but manageable burden, and $6.7 \%$ perceived no burden at all. The influencing factors associated with the expense-income ratio and the proportion of families with an unmanageable burden coincide with each other quite well; moreover, these factors were also allied with the overall expenditure of CRC patients in China.

Compared with patients from general hospitals, patients from specialized hospitals tended to have a higher expense-income ratio $(0.684$ vs. $0.432, P<0.001)$ and more families with unmanageable burden $(76.4 \%$ vs. $71.4 \%, P<0.001)$. Similarly, patients who were diagnosed at an earlier age (younger than 45 years) were likely to expend more than those diagnosed at older age $(P=0.019)$; among these patients, $79.6 \%$ experienced an unmanageable burden. The expense-income ratio for patients with poor education (i.e., primary school or less) was 0.769 , making $84.0 \%$ of them experience an unmanageable burden, which was much higher than that of well-educated patients $(P<0.001)$. The gap was even apparent in terms of the household income: those with lower household income (i.e., less than 20,000 CNY) spent a larger share of the household income for CRC diagnosis and treatment, and more families felt stressed $(P<0.001)$. Those with income lower than $20,000 \mathrm{CNY}$ spent more than three times their household income for CRC diagnosis and treatment, making $92.3 \%$ of these families unable to afford treatment. In terms of therapeutic regimen, the expense-income ratios of patients who received symptomatic treatment and those who received neoadjuvant chemotherapy and surgery were the lowest and highest $(0.489$ vs. $1.192, P<0.001)$; the proportion of families who perceived an unmanageable burden was lowest for patients who received symptomatic treatment and highest for those who received radiotherapy $(69.0 \%$ vs. $85.7 \%, P<0.001)$. Although the expense-income ratio was similar among patients with CRC of various stages $(P=0.054)$, we still found that families of stage IV CRC patients suffered the highest pressure $(27.8 \%$ heavy, $50.9 \%$ overwhelmed; $P<0.001)$. As expected, the expense-income ratio of farmers was the highest $(0.977$, $P<0.001$ ): $90.1 \%$ of farmer families found treatment expenses unmanageable. However, patients who had new rural cooperative medical scheme insurance faced a similar dilemma and spent $85.8 \%$ of their household income, resulting in $88.6 \%$ of these families experiencing unmanageable financial burden. Neither the expense-income ratio nor financial pressure was statistically sensitive to sex $(P=0.053)$ or pathologic type $(P=0.083)$. More information about the financial burden of overall expenditure is shown in Table 5.

\section{Time loss}

Mean overall time loss amounted to 95.9 persondays -54.0 person-days $(56.3 \%)$ for patients and 41.9 person-days (43.7\%) for caregivers. If crudely converted by the 2014 minimum monthly wage of $1560 \mathrm{CNY}$ in Beijing [15], mean wage loss amounted to $6652 \mathrm{CNY}$. Patients from specialized hospitals $(P<0.001)$ or those who were diagnosed with adenocarcinoma $(P=0.026)$ suffered 
Table 4 Multivariate analysis of overall expenditure for diagnosis and treatment of $\mathbf{2 3 5 6}$ patients with colorectal cancer

\begin{tabular}{|c|c|c|}
\hline Characteristic & Estimate $(95 \% \mathrm{Cl})$ & $P$ \\
\hline Intercept & $10.4(10.2,10.5)$ & $<0.001$ \\
\hline \multicolumn{3}{|l|}{ Hospital type (Ref = general) } \\
\hline Specialized & $0.2(0.1,0.2)$ & $<0.001$ \\
\hline \multicolumn{3}{|l|}{ Age at diagnosis (years) (Ref $=\geq 65$ ) } \\
\hline$<45$ & $0.0(-0.1,0.1)$ & 0.419 \\
\hline $45-54$ & $0.1(0.0,0.2)$ & 0.131 \\
\hline $55-64$ & $0.0(-0.1,0.1)$ & 0.522 \\
\hline \multicolumn{3}{|l|}{ Sex (Ref = women) } \\
\hline Men & $0.0(-0.1,0.1)$ & 0.969 \\
\hline \multicolumn{3}{|l|}{ Education (Ref = primary school or below) } \\
\hline Junior high school & $0.0(-0.1,0.1)$ & 0.815 \\
\hline Senior high school & $0.0(0.0,0.1)$ & 0.310 \\
\hline Undergraduate or higher & $0.1(0,0.2)$ & 0.134 \\
\hline \multicolumn{3}{|c|}{ Occupation (Ref $=$ self-employee or unemployee) } \\
\hline Farmer & $0.0(-0.1,0.2)$ & 0.493 \\
\hline Enterprise or company employee/worker & $-0.1(-0.2,0.0)$ & 0.057 \\
\hline Retiree & $0.1(-0.1,0.2)$ & 0.377 \\
\hline Public sector employee & $0.2(0.1,0.3)$ & 0.004 \\
\hline Other & $0.0(-0.3,0.2)$ & 0.778 \\
\hline \multicolumn{3}{|l|}{$\begin{array}{l}\text { Healthcare insurance type (Ref }=\text { new rural } \\
\text { cooperative medical scheme) }\end{array}$} \\
\hline Urban employee basic medical insurance & $0.0(-0.1,0.1)$ & 0.641 \\
\hline Urban resident basic medical insurance & $0.0(-0.1,0.1)$ & 0.707 \\
\hline Commercial insurance & $0.0(-0.3,0.4)$ & 0.792 \\
\hline Self-paid & $0.0(-0.2,0.2)$ & 0.905 \\
\hline Other & $0.4(0.1,0.7)$ & 0.020 \\
\hline \multicolumn{3}{|c|}{ Previous-year household income (CNY) (Ref $=\leq 20,000)$} \\
\hline $20,000-39,999$ & $0.1(0.0,0.2)$ & 0.006 \\
\hline $40,000-69,999$ & $0.1(0.0,0.2)$ & 0.046 \\
\hline$\geq 70,000$ & $0.1(0.0,0.2)$ & 0.006 \\
\hline \multicolumn{3}{|l|}{ Clinical stage $(\operatorname{Ref}=\mathrm{I})$} \\
\hline$\|$ & $0.0(-0.1,0.1)$ & 0.822 \\
\hline III & $0.1(0.0,0.2)$ & 0.099 \\
\hline IV & $0.3(0.1,0.4)$ & $<0.001$ \\
\hline \multicolumn{3}{|l|}{ Pathologic type (Ref $=$ others) } \\
\hline Adenocarcinoma & $0.2(0.1,0.3)$ & $<0.001$ \\
\hline \multicolumn{3}{|l|}{ Therapeutic regimen (Ref $=$ surgery) } \\
\hline Chemotherapy & $0.2(0.1,0.3)$ & $<0.001$ \\
\hline Surgery and postoperative chemotherapy & $0.2(0.1,0.3)$ & $<0.001$ \\
\hline Symptomatic treatment & $0.1(0.0,0.2)$ & 0.170 \\
\hline Concurrent chemoradiotherapy & $0.8(0.6,1.0)$ & $<0.001$ \\
\hline Radiotherapy & $0.5(0.3,0.7)$ & $<0.001$ \\
\hline Neoadjuvant chemotherapy and surgery & $0.2(-0.2,0.6)$ & 0.251 \\
\hline
\end{tabular}

CNY Chinese Yuan, $\mathrm{Cl}$ confidence interval

relatively more time loss than patients from general hospitals or those who were diagnosed with other pathologic types; conversely, patients who were self-employed or

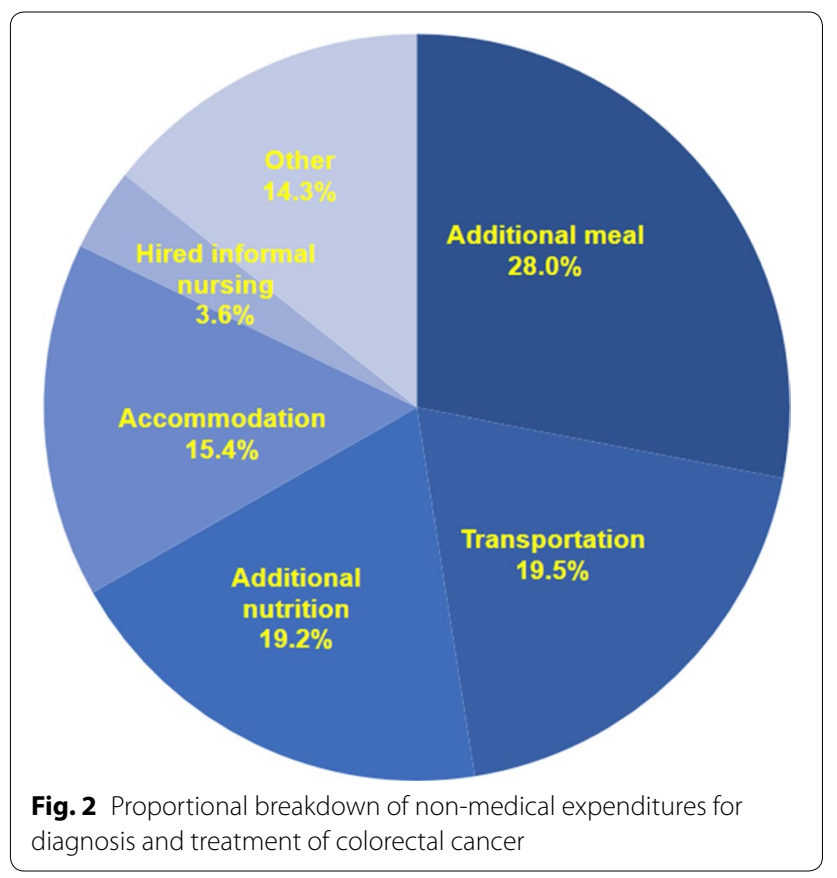

unemployed $(P<0.001)$, covered by the Urban Resident Basic Medical Insurance or underinsured $(P=0.003)$, diagnosed with stage I-II disease $(P<0.001)$, or underwent surgery $(P<0.001)$ suffered less than their corresponding control groups. Nevertheless, when stratified by age at diagnosis $(P=0.516)$, sex $(P=0.191)$, education $(P=0.138)$, or household income $(P=0.219)$, no difference was observed. Detailed findings for time loss are shown in Table 6.

\section{Discussion}

Our study provided much-needed data on direct medical and non-medical expenditures associated with prevalent CRC and the resulting financial burden. We found that direct expenditure was catastrophic and burdensome and varied greatly among different subgroups.

In our study, we found that the mean direct expenditure per CRC patient was 67,408 CNY. According to a recent review of the financial burden of CRC in China, only one study included both medical and non-medical expenditures per patient; others focused only on medical expenditure [9]. The earliest study was reported in 1999, and the most recent was in 2014 [9]. Except for one study ( 50,000 CNY), all others showed expenses amounting to less than half of that in our study $(61,829 \mathrm{CNY})$, mainly because of their relatively short course and our uncovering of expenses outside the surveyed hospitals [9]. According to the latest data published in Lancet, CRC was the most costly cancer among the six most common cancers in urban China [16]. Compared internationally, 


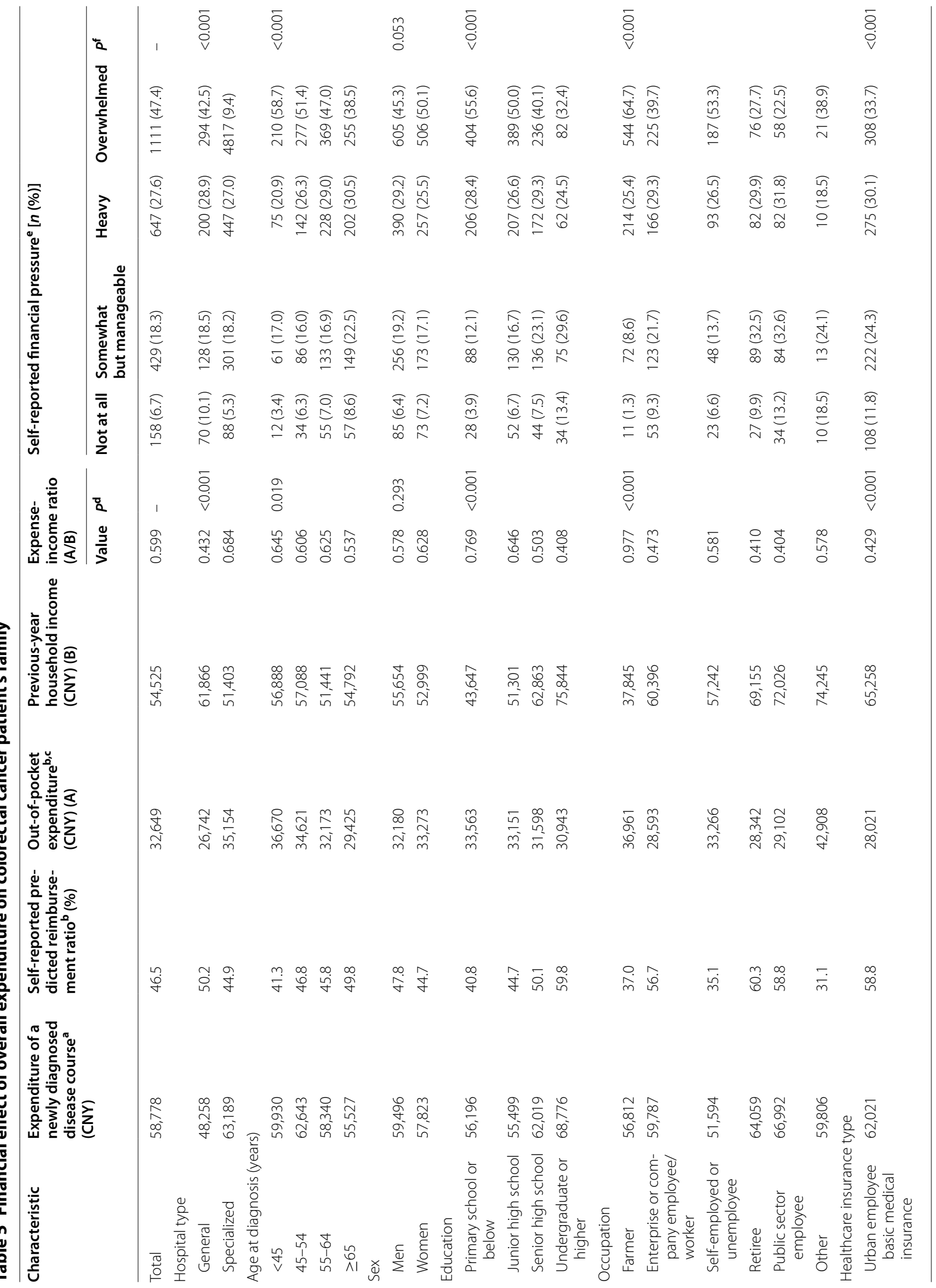




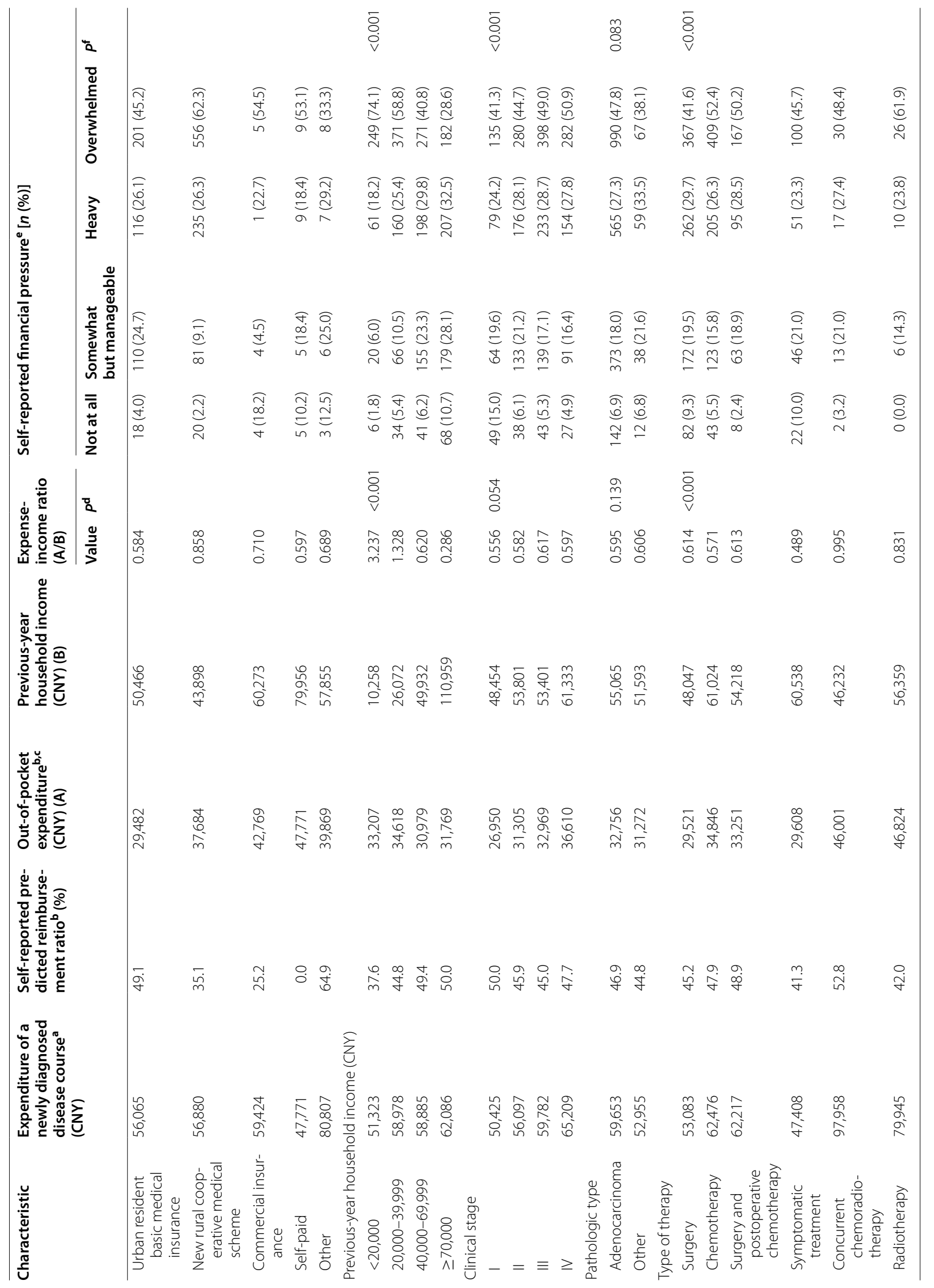




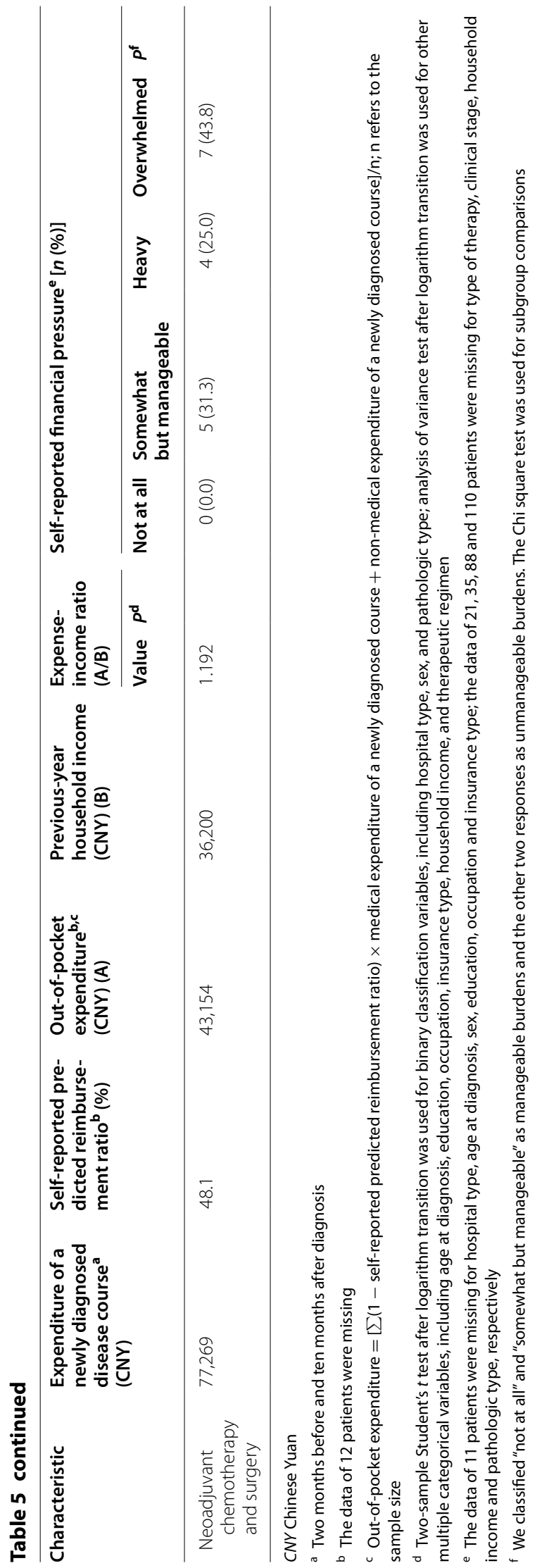


Table 6 Time loss due to colorectal cancer diagnosis and treatment

\begin{tabular}{|c|c|c|c|c|c|}
\hline \multirow[t]{2}{*}{ Characteristic } & \multicolumn{3}{|c|}{ Time loss (person-days) $^{a}$} & \multirow[t]{2}{*}{ Statistics $^{\mathbf{b}}$} & \multirow[t]{2}{*}{$P^{b}$} \\
\hline & Overall & Patients & Caregivers & & \\
\hline Total & 95.9 & 54.0 & 41.9 & - & - \\
\hline \multicolumn{6}{|l|}{ Hospital type } \\
\hline General & 40.0 & 38.7 & 78.6 & \multirow[t]{2}{*}{-4.10} & \multirow[t]{2}{*}{$<0.001$} \\
\hline Specialized & 59.9 & 43.3 & 103.2 & & \\
\hline \multicolumn{6}{|l|}{ Age at diagnosis (years) } \\
\hline$<45$ & 103.5 & 61.7 & 41.7 & \multirow[t]{4}{*}{0.76} & \multirow[t]{4}{*}{0.516} \\
\hline $45-54$ & 98.3 & 55.6 & 42.7 & & \\
\hline $55-64$ & 95.4 & 53.6 & 41.8 & & \\
\hline$\geq 65$ & 90.7 & 49.0 & 41.6 & & \\
\hline \multicolumn{6}{|l|}{ Sex } \\
\hline Men & 98.8 & 55.7 & 43.1 & \multirow[t]{2}{*}{1.31} & \multirow[t]{2}{*}{0.191} \\
\hline Women & 92.2 & 51.8 & 40.3 & & \\
\hline \multicolumn{6}{|l|}{ Education } \\
\hline Primary school or below & 95.4 & 53.7 & 41.7 & \multirow[t]{4}{*}{1.84} & \multirow[t]{4}{*}{0.138} \\
\hline Junior high school & 94.9 & 54.3 & 40.6 & & \\
\hline Senior high school & 95.2 & 52.0 & 43.2 & & \\
\hline Undergraduate or higher & 102.6 & 58.7 & 43.9 & & \\
\hline \multicolumn{6}{|l|}{ Occupation } \\
\hline Farmer & 101.1 & 58.1 & 43.0 & \multirow[t]{6}{*}{4.80} & \multirow[t]{6}{*}{$<0.001$} \\
\hline Enterprise or company employee/worker & 98.8 & 53.7 & 45.1 & & \\
\hline Self-employee or unemployee ununemployee & 78.8 & 45.8 & 33.0 & & \\
\hline Retiree & 93.5 & 52.7 & 40.8 & & \\
\hline Public sector employee & 98.6 & 53.8 & 44.8 & & \\
\hline Others & 96.5 & 52.9 & 43.6 & & \\
\hline \multicolumn{6}{|l|}{ Healthcare insurance type } \\
\hline Urban employee basic medical insurance & 99.7 & 54.6 & 45.0 & \multirow[t]{6}{*}{3.64} & 0.003 \\
\hline Urban resident basic medical insurance & 82.2 & 43.3 & 38.9 & & \\
\hline New rural cooperative medical scheme & 99.3 & 58.8 & 40.4 & & \\
\hline Commercial insurance & 87.0 & 60.4 & 26.5 & & \\
\hline Self-paid & 85.0 & 46.2 & 38.8 & & \\
\hline Other & 127.0 & 65.0 & 62.0 & & \\
\hline Previous-year household income (CNY) & & & & & \\
\hline$<20,000$ & 98.1 & 56.1 & 42.0 & 1.48 & 0.219 \\
\hline $20,000-39,999$ & 99.3 & 57.3 & 42.0 & & \\
\hline $40,000-69,999$ & 96.7 & 54.5 & 42.2 & & \\
\hline$\geq 70,000$ & 92.1 & 50.3 & 41.8 & & \\
\hline Clinical stage & & & & & \\
\hline I & 76.1 & 40.1 & 36.0 & 16.05 & $<0.001$ \\
\hline$\|$ & 77.4 & 42.8 & 34.6 & & \\
\hline III & 98.0 & 55.6 & 42.4 & & \\
\hline IV & 126.8 & 73.7 & 53.1 & & \\
\hline Pathologic type & & & & & \\
\hline Adenocarcinoma & 97.0 & 55.0 & 42.0 & 2.25 & 0.026 \\
\hline Others & 82.4 & 46.6 & 35.8 & & \\
\hline Therapeutic regimen & & & & & \\
\hline Surgery & 70.6 & 39.9 & 30.7 & 18.28 & $<0.001$ \\
\hline Chemotherapy & 115.7 & 66.1 & 49.6 & & \\
\hline Surgery and postoperative chemotherapy & 98.2 & 55.8 & 42.5 & & \\
\hline
\end{tabular}


Table 6 continued

\begin{tabular}{|c|c|c|c|c|c|}
\hline \multirow[t]{2}{*}{ Characteristic } & \multicolumn{3}{|c|}{ Time loss (person-days) ${ }^{a}$} & \multirow[t]{2}{*}{ Statistics $^{\mathbf{b}}$} & \multirow[t]{2}{*}{$P^{\mathbf{b}}$} \\
\hline & Overall & Patients & Caregivers & & \\
\hline Symptomatic treatment & 93.3 & 49.2 & 44.1 & & \\
\hline Concurrent chemoradiotherapy & 196.2 & 103.0 & 93.2 & & \\
\hline Radiotherapy & 188.0 & 105.1 & 82.9 & & \\
\hline Neoadjuvant chemotherapy and surgery & 91.8 & 53.7 & 38.1 & & \\
\hline
\end{tabular}

CNY Chinese Yuan

a The data of 89 patients were missing

b Two-sample Student's $t$ test after logarithm transition was used for binary classification variables, including hospital type, sex, and pathologic type; analysis of variance test after logarithm transition was used for other multiple categorical variables, including age at diagnosis, education, occupation, insurance type, household income, and therapeutic regimen

the absolute quantity of overall expenditure in China was much less than that in the United States and Canada [17, 18]. The ratio of the expenditure in annual GDP per capita was 1.4 and 0.6 in our survey, whereas that for both the United States and Canada was lower than 1.0 [19].

We found that several variables were significant for overall expenditure, including hospital type, occupation, household income, clinical stage, pathologic type, and therapeutic regimen. Notably, in line with a recent research [20] and review [21], we found that expenditure was higher for patients with late stage (stage III and IV) CRC than for those with early stage (stage I and II) CRC, which may be linked to longer hospitalization stays and more expensive treatments, such as targeted biological therapies. In contrast, patients with stage I disease mostly underwent surgery and spent much less. These findings suggest the potential cost-effectiveness of early detection and treatment. Although we attempted to balance stage-specific cases, only $13.9 \%$ of all cases were stage I, which reflects the lack of early diagnosis and treatment. However, under the resource and financial constraints in China, policymakers require more evidence of cost-effectiveness before expanding the scope of CRC screening.

Additionally, we found that non-medical expenditure for the diagnosis and treatment of CRC was a significant component, reaching $8.3 \%$ of the overall expenditure. It was higher than that found in the only previous relevant study in China (5.4\%) [22]. Of the 55 overseas studies on financial burden, only nine investigated non-medical expenditure. The detailed non-medical expenditure were mainly comprising the wage losses of both caregivers and patients [23], which was different from those reported by Drummond et al. [24] and Cheng et al. [25], as well as those reported in our study.

Regarding time loss, CRC diagnosis and treatment caused an average wage loss of 1560 CNY, accounting for 3.3\% of GDP per capita of China in 2014, which was substantially underestimated. The ratio of wage loss in annual GDP per capita for the only previous study in China was $12.2 \%$ [22], whereas those found in studies in the United States and in Canada were 25.6\% [26] and $289.5 \%$ [27], respectively. This substantial gap could be partly explained by the low labor cost and special healthcare delivery model in China and potentially by methodological differences. Numeric differences exist among these studies, but it is more important to observe the consistent conclusions and directions. The time loss of both patients and caregivers was a considerable component of the financial burden, and more attention was recently paid to time cost and productivity cost [28-30]. However, in China, these components have been rarely calculated previously [9].

Obviously, much work remains to determine the comprehensive expenditure, especially including direct nonmedical expenditure, indirect expenditure, and intangible expenditure. Moreover, in China, no attention has been given to lifetime expenditure or specifics such as treatment phase (initial, continuing, or terminal). In studies of financial burden, opportunities and challenges coexist.

Concerning financial burden, patients spent 59.9\% of their household income for one year of CRC diagnosis and treatment, and $75.0 \%$ of the families perceived an unmanageable financial burden. In contrast, in the United States, $25.0 \%$ of insured patients spent approximately one-third of their annual income on healthcare, and $39.9 \%$ spent approximately one-fifth of their annual income [30]. In Canada, the proportion of patients who perceived an unmanageable financial burden was only $3.9 \%$; even including those who perceived a significant but manageable burden, it came to only $20.4 \%$ [31], which was much lower than that in our study. Thus, we can surmise that the plight of CRC patients and their families in China is worse than that of CRC patients in the United States and Canada. Heterogeneity in terms of data source or methodology occasionally makes it difficult to compare across studies; nevertheless, such a large gap does deserve the government's attention. Developing corresponding policies to control out-of-pocket expenses 
can help patients and their families in China better cope with serious diseases such as cancer.

Several key influencing factors for the expense-income ratio and the proportion of families perceiving an unmanageable financial burden were found to be similar to those for overall expenditure, which perhaps was not coincidental when we combined evidence reported elsewhere [32-34]. Notably, patients in the lowest household income group were in the worst financial situation, although the absolute quantity of expenditure was the least. Not surprisingly, the inability to pay prevents them from receiving sufficient healthcare [35]. Well-educated patients generally had higher incomes and spent more but were less stressed compared with their control groups. Because farmers generally had new rural cooperative medical scheme insurance and lower income, it seems self-evident that their direct expenditure was the lowest, and vice versa for public sector employees or retirees. These differences suggest that, in keeping with principles of justice and fairness, health service delivery reforms, such as to the medical insurance system, should consider providing more assistance to vulnerable populations.

This survey had several limitations. First, recall bias may have resulted from the retrospective nature of the questionnaire survey. Second, selection bias may have resulted from high-level hospitals and non-random sampling, although in China CRC patients are almost exclusively treated in tertiary hospitals. Third, the expenditure may have been underestimated because it covered only the to-date whole course. Another issue is risk factors for high expenditure; further multiple factor analysis is needed. Finally, although we could determine the potential effect of wage loss on perceived financial pressure, we considered only medical and non-medical expenditures.

\section{Conclusions}

Research on calculating the financial burden of CRC in China is still in its initial phase, and more is needed. We found that, for patients in China, expenditure for diagnosis and treatment of CRC seemed catastrophic, and nonmedical expenditure cannot be ignored. Expenditure and financial burden varied among subgroups, especially for patients with disease of different clinical stages, suggesting that, in China, CRC screening might be cost-effective. Our findings also support the policy of medical insurance and payment system reform for affordable and equitable access to quality healthcare, which should be considered before further research on comprehensive expenditure is done.

\section{Abbreviations}

CRC: colorectal cancer; CanSPUC: Cancer Screening Program in Urban China; CNY: Chinese Yuan.

\section{Authors' contributions}

HYH contributed to framework planning and draft writing, as well as data quality control, analysis, and interpretation. JFS led the health economic study design, overall analysis framework planning, and data interpretation. LWG, XYZ, LW, and DS supported data quality control, analysis, and interpretation. YNB, XZL, GXL, AYM, JSR, and XJS were the expert panel of the Health Economic Evaluation Working Group of the CanSPUC program, contributing to field data collection and participating in data analysis planning. BBS, LBD, $L Z$, JYG, QZ, YQL, RC, LM, LL, XHS, YR, JYZ, YZW, XQ, and PAL contributed to field data collection. MD, KZ, and JH contributed the overall design and were the co-managers of the Cancer Screening Program in Urban China. All authors read and approved the final manuscript.

\section{Author details}

${ }^{1}$ Program Office for Cancer Screening in Urban China, National Cancer Center/Cancer Hospital, Chinese Academy of Medical Sciences, Peking Union Medical College, 17 South Panjiayuan Lane, Chaoyang District, Beijing 100021, P. R. China. ${ }^{2}$ Department of Cancer Epidemiology, Henan Cancer Hospital, Affiliated Cancer Hospital of Zhengzhou University, Zhengzhou, Henan 450008, P. R. China. ${ }^{3}$ Institute of Epidemiology and Health Statistics, Lanzhou University, Lanzhou, Gansu 730000, P. R. China. ${ }^{4}$ Hunan Office for Cancer Control and Research, Hunan Provincial Cancer Hospital, Changsha, Hunan 410006, P. R. China. ${ }^{5}$ Department of Health Economics, School of Health Management, Harbin Medical University, Harbin, Heilongjiang 150081, P. R. China.

${ }^{6}$ Public Health Information Research Office, Institute of Medical Information, Chinese Academy of Medical Sciences, Beijing 100020, P. R. China. ${ }^{7}$ Center for Health Management and Policy, Key Lab of Health Economics and Policy, Shandong University, Jinan, Shandong 250012, P. R. China. ${ }^{8}$ Heilongjiang Office for Cancer Control and Research, Affiliated Cancer Hospital of Harbin Medical University, Harbin, Heilongjiang 150081, P. R. China. ${ }^{9}$ Zhejiang Office for Cancer Control and Research, Zhejiang Cancer Hospital, Hangzhou, Zhejiang 310022, P. R. China. ${ }^{10}$ Teaching and Research Department, Affiliated Cancer Hospital of Xinjiang Medical University, Ürümqi, Xinjiang 830011, P.

R. China. ${ }^{11}$ Science and Education Department of Public Health Division, Shandong Tumor Hospital, Jinan, Shandong 250117 , P. R. China. ${ }^{12}$ Chongqing Office for Cancer Control and Research, Chongqing Cancer Hospital, Chongqing 400030, P. R. China. ${ }^{13}$ Cancer Epidemiology Research Center, Gansu Provincial Cancer Hospital, Lanzhou, Gansu 730050, P. R. China. ${ }^{14}$ Department of Health Policy and Economic Research, Guangdong Provincial Institute of Public Health, Guangzhou, Guangdong 511430, P. R. China. ${ }^{15}$ Department of Institute of Tumor Research, Henan Cancer Hospital, Affiliated Cancer Hospital of Zhengzhou University, Zhengzhou, Henan 450008, P. R. China. ${ }^{16}$ Institute of Chronic Disease Prevention and Control, Harbin Center for Disease Control and Prevention, Harbin, Heilongjiang 150081, P. R. China. ${ }^{17}$ Ningbo Clinical Cancer Prevention Guidance Center, Ningbo No. 2 Hospital, Ningbo, Zhejiang 315010, P. R. China. ${ }^{18}$ Urban Office of Cancer Early Detection and Treatment, Tieling Central Hospital, Tieling, Liaoning 112000, P. R. China.

${ }^{19}$ Institute of Chronic Non-communicable Diseases Prevention and Control, Jiangsu Provincial Center for Disease Control and Prevention, Nanjing, Jiangsu 210009, P. R. China. ${ }^{20}$ Department of Economic Operation, Kailuan General Hospital, Tangshan, Hebei 063000, P. R. China. ${ }^{21}$ Department of Occupational Medicine, Tangshan People's Hospital, Tangshan, Hebei 063000, P. R. China.

${ }^{22}$ Department of Control and Prevention of Chronic Non-communicable Diseases, Xuzhou Center for Disease Control and Prevention, Xuzhou, Jiangsu 221006, P. R. China.

\section{Acknowledgements}

We thank all the participants, without whom this survey would not have been possible. We also thank all the staff involved in the CanSPUC for their hard work and dedication, including experts from the National Cancer Center of China, field personnel in 13 provinces, and the external expert panel.

\section{Competing interests}

The authors declare that they have no competing interests.

\section{Grant support}

This study was supported by the grants from the Beijing Hope Run Special Fund (\# LC2012YF44), National Natural Science Foundation of China (No. 81402740), Specialized Research Fund for the Doctoral Program of Higher Education (No. 20131106120014), and The National Health and Family Planning Committee of P. R. China. 
Received: 6 July 2016 Accepted: 8 December 2016 Published online: 28 April 2017

\section{References}

1. Ferlay J, Soerjomataram I, Ervik M, Dikshit R, Eser S, Mathers C, et al. GLOBOCAN 2012 v1.0, Cancer Incidence and Mortality Worldwide: IARC CancerBase No. 11. Lyon, France: International Agency for Research on Cancer, December 2013. http://globocan.iarc.fr. Accessed 2 Oct 2015.

2. Chen $\mathrm{W}$, Zheng $\mathrm{R}$, Zeng $\mathrm{H}$, Zhang $\mathrm{S}$. The incidence and mortality of major cancers in China, 2012. Chin J Cancer. 2016;35(1):73. doi:10.1186/ s40880-016-0137-8.

3. Sullivan R, Peppercorn J, Sikora K, Zalcberg J, Meropol NJ, Amir E, et al. Delivering affordable cancer care in high-income countries. Lancet Oncol. 2011;12(10):933-80. doi:10.1016/s1470-2045(11)70141-3.

4. Arndt V, Merx H, Stegmaier C, Ziegler $\mathrm{H}$, Brenner $\mathrm{H}$. Restrictions in quality of life in colorectal cancer patients over three years after diagnosis: a population based study. Eur J Cancer. 2006;42(12):1848-57. doi:10.1016/j. ejca.2006.01.059.

5. Cotrim H, Pereira G. Impact of colorectal cancer on patient and family: implications for care. Eur J Oncol Nurs. 2008;12(3):217-26. doi:10.1016/j. ejon.2007.11.005.

6. Maher J, McConnell H. New pathways of care for cancer survivors: adding the numbers. Br J Cancer. 2011;105(Suppl 1):S5-10. doi:10.1038/ bjc.2011.417.

7. Altice CK, Banegas MP, Tucker-Seeley RD, Yabroff KR. Financial hardships experienced by cancer survivors: a systematic review. J Natl Cancer Inst. 2017;109(2):205. doi:10.1093/jnci/djw205.

8. Girgis A, Lambert S, Johnson C, Waller A, Currow D. Physical, psychosocial, relationship, and economic burden of caring for people with cancer: a review. J Oncol Pract. 2013;9(4):197-202. doi:10.1200/jop.2012.000690.

9. Shi JF, Shi CL, Yue XP, Huang HY, Wang L, Li J, et al. Economic burden of cancer in China during 1996-2014: a systematic review. Chinese Health Econ. 2016;38(12):929-41 (in Chinese).

10. Yip W, Hsiao W. Harnessing the privatisation of China's fragmented health-care delivery. Lancet. 2014;384(9945):805-18. doi:10.1016/ s0140-6736(14)61120-x.

11. Dai M, Shi JF, Li N. Cancer Screening Program in Urban China: the program design and the expectancies. Zhonghua Yu Fang Yi Xue Za Zhi. 2013:47(2):179-82 (in Chinese)

12. Huang HY, Shi JF, Dai M. Reasearch progress in health economic evaluation of colorectal cancer screening in China. Zhonghua Yu Fang Yi Xue Za Zhi. 2015;8:747-51. doi:10.3760/cma.j.issn.0253-9624.2015.08.017 (in Chinese)

13. National Bureau of Statistics of China. China statistical yearbook, 2015. http://www.stats.gov.cn/tjsj/ndsj/2015/indexch.htm. Accessed 5 Jun 2016 (in Chinese).

14. Xu K, Evans DB, Carrin G, Aguilar-Rivera AM, Musgrove P, Evans T. Protecting households from catastrophic health spending. Health Aff (Millwood). 2007;26(4):972-83. doi:10.1377/hlthaff.26.4.972.

15. Beijing Human Resources and Social Security Bureau. http://www. bjldgovcn/LDJAPP/search/searchdetailjsp?no=28109. Accessed 3 Jun 2015 (in Chinese).

16. Huang HY, Shi JF, Guo LW, Zhu XY, Wang L, Liao XZ, et al. Expenditure and financial burden for common cancers in China: a hospital-based multicentre cross-sectional study. Lancet. 2016;388:S10.

17. Lang K, Lines LM, Lee DW, Korn JR, Earle CC, Menzin J. Lifetime and treatment-phase costs associated with colorectal cancer: evidence from SEER-Medicare data. Clin Gastroenterol Hepatol. 2009;7(2):198-204. doi:10.1016/j.cgh.2008.08.034.

18. Shankaran V, Jolly S, Blough D, Ramsey SD. Risk factors for financial hard ship in patients receiving adjuvant chemotherapy for colon cancer: a population-based exploratory analysis. J Clin Oncol. 2012;30(14):1608-14. doi:10.1200/JCO.2011.37.9511

19. The World Bank. GDP per capita based on purchasing power parity (PPP). http://data.worldbank.org/indicator. Accessed 10 Oct 2015.
20. Hall PS, Hamilton P, Hulme CT, Meads DM, Jones H, Newsham A, et al. Costs of cancer care for use in economic evaluation: a UK analysis of patient-level routine health system data. Br J Cancer. 2015;112(5):948-56. doi:10.1038/bjc.2014.644.

21. Kriza C, Emmert M, Wahlster P, Niederlander C, Kolominsky-Rabas $P$. An international review of the main cost-effectiveness drivers of virtual colonography versus conventional colonoscopy for colorectal cancer screening: is the tide changing due to adherence? Eur J Radiol. 2013:82(11):e629-36. doi:10.1016/j.ejrad.2013.07.019.

22. Xu WY, Shi W, Chen P. Analysis of economic burden of malignant tumor in-patients in Xinjiang. Ji Bing Jian Ce. 2006;21(1):38-40 (in Chinese)

23. Yabroff KR, Borowski L, Lipscomb J. Economic studies in colorectal cancer: challenges in measuring and comparing costs. J Natl Cancer Inst Monogr. 2013;2013(46):62-78. doi:10.1093/jncimonographs/lgt001.

24. Drummond MF, Sculpher MJ, Torrance GW, O'Brien BJ, Stoddart GL. Methods for the economic evaluation of health care programmes. Oxford: Oxford University Press; 2005.

25. Cheng XM, Wj Luo, Liu GX, Ma J, Meng QY, Wang XW, et al. Health Economics. Beijing: People's Medical Publishing House; 2012 (in Chinese).

26. Van Houtven $\mathrm{CH}$, Ramsey SD, Hornbrook MC, Atienza AA, van Ryn M. Economic burden for informal caregivers of lung and colorectal cancer patients. Oncologist. 2010;15(8):883-93. doi:10.1634/ theoncologist.2010-0005.

27. Hopkins RB, Goeree R, Longo CJ. Estimating the national wage loss from cancer in Canada. Curr Oncol. 2010;17(2):40-9.

28. Hanly P, Soerjomataram I, Sharp L. Measuring the societal burden of cancer: the cost of lost productivity due to premature cancer-related mortality in Europe. Int J Cancer. 2015;136(4):E136-45. doi:10.1002/ijc.29105.

29. Hollenbeak CS, Short PF, Moran J. The implications of cancer survivorship for spousal employment. J Cancer Surviv. 2011;5(3):226-34. doi:10.1007/ s11764-011-0175-9.

30. Neuman P, Cubanski J, Desmond KA, Rice TH. How much'skin in the game' do medicare beneficiaries have? The increasing financial burden of health care spending, 1997-2003. Health Aff (Millwood). 2007;26(6):1692701. doi:10.1377/hlthaff.26.6.1692.

31. Longo CJ, Fitch M, Deber RB, Williams AP. Financial and family burden associated with cancer treatment in Ontario, Canada. Support Care Cancer. 2006;14(11):1077-85. doi:10.1007/s00520-006-0088-8.

32. Mathews M, West R, Buehler S. How important are out-of pocket costs to rural patients' cancer care decisions? Can J Rural Med. 2009;14:54-60.

33. Weaver KE, Rowland JH, Alfano CM, McNeel TS. Parental cancer and the family: a population-based estimate of the number of US cancer survivors residing with their minor children. Cancer. 2010;116(18):4395-401. doi:10.1002/cncr.25368.

34. Shi Q, Smith TG, Michonski JD, Stein KD, Kaw C, Cleeland CS. Symptom burden in cancer survivors 1 year after diagnosis: a report from the American Cancer Society's Studies of Cancer Survivors. Cancer. 2011;117(12):2779-90. doi:10.1002/cncr.26146.

35. Puts MT, Tu HA, Tourangeau A, Howell D, Fitch M, Springall E, et al. Factors influencing adherence to cancer treatment in older adults with cancer: a systematic review. Ann Oncol. 2014;25(3):564-77. doi:10.1093/annonc/ mdt433.

\section{Submit your next manuscript to BioMed Central and we will help you at every step:}

- We accept pre-submission inquiries

- Our selector tool helps you to find the most relevant journal

- We provide round the clock customer support

- Convenient online submission

- Thorough peer review

- Inclusion in PubMed and all major indexing services

- Maximum visibility for your research

Submit your manuscript at www.biomedcentral.com/submit 